\title{
A LOGARITHMIC SPECTRAL APPROACH TO FERRORESONANCE PHENOMENA
}

\author{
Jelena Dikun ${ }^{1}$, Tahir Cetin Akinci ${ }^{2}$ \& Serhat Seker ${ }^{2}$ \\ ${ }^{1}$ Klaipeda University, Department of Electrical Engineering \\ Klaipeda, Lithuania, e-mail: jeldik@bk.ru \\ ${ }^{2}$ Istanbul Technical University, Department of Electrical Engineering \\ Maslak, Istanbul, Turkey, e-mail:akincitc@itu.edu.tr, sekers@itu.edu.tr
}

\begin{abstract}
In this study, modelling of Oymapinar transmission lions of the West Anatolian Power System region in Turkey is considered. For the modelling, the Matlab-Simulink is used and the ferroresonance phenomena is applied with a switching operation on this modelling. Collected data shows the overvoltage characteristic of a natural results of the ferroresonance event. In this manner this is the non-stationary data and it can be separated two stationary parts like before and after the switching and Power Spectral Density (PSD) functions are calculated in the logarithmic scale of the amplitudes. Hence, as a result of the ferroresonance phenomena, gain changes in the spectral amplitudes are presented in decibel units. This is given an observable result in the logarithmic spectral domain of the overvoltage effect.
\end{abstract}

Keywords: Ferroresonance, Power System Modelling, Power Spectrum Density (PSD), Spectral Amplitude Gain.

\section{INTRODUCTION}

Ferroresonance a complex electrical event. However, ferroresonance event is known since 1920 , today's power systems research is among the least known events. Ferroresonance phenomenon was defined as the incidence that occurs suddenly at high voltage and causes high level harmonic distortions. Ferroresonance can be caused by faults such as line breaks and lightning. Ferroresonance an unwanted event in the electric power system, the result of ferroresonance fault system can be dragged into chaos. After ferroresonance fault system on overvoltage occurs, and this over voltages damages to equipment on the electric power transmission line.

Ferroresonance phenomenon was defined as the incidence that occurs suddenly at high voltage and causes high level harmonic distortions. The concept of ferroresonance that firstly appeared in 1920s recalls all oscillation cases which occur in an electrical circuit and includes at least the following elements:

- Non-lineer inductance;

- A Capacity;

- A voltage source;

- Low losses.

To avoid the fault ferroresonance following precautions should be taken. Long electrical transmission lines should be avoided. Grounding should be performed well. Transmission lines must be protected against lightning. Sudden discharges, and switching effects should be minimized. Today ferroresonance failures in transmission lines described as the most dangerous faults. In this study; Oymapinar electric power system is modelled, and the effects of the ferroresonance were investigated. 


\section{IRTTIE $Y^{2}$}

Ipplied Resseirlores in Technics, Technologies and Educration Journal of the Faculty of Technics and Technologies, Trakia University https://sites.google.com/a/trakia-uni.bg/artte/

In this study, the power system is modelled for ferroresonance conditions. For the data obtained from the model, spectral analysis was performed. In addition, a logarithmic approximation model was applied.

\section{LOGARITMIC AUTO-POWER SPECTRAL DENSITY}

The PSD is the average value of the magnitude squared of the Fourier transform. In this manner, for a given time domain signal $x(t)$, its Fourier transform can be defined between periods of $\pm T$. Equations can be seen in equations (1) and (2).

$$
X(j \omega) \square F\{x(t)\}=\int_{-T}^{T} \mathrm{x}(\mathrm{t}) e^{-j \omega t} d t
$$

here its magnitude square is given Eq.(2).

$$
|X|^{2}=X(j \omega) X(-j \omega)=X . X^{*}
$$

and finally Auto-Power Spectral Density function $\operatorname{Sxx}(f)$ is described as follow Eqs. (3) and (4).

$$
S_{x x}(f)=\lim _{T \rightarrow \infty} \frac{1}{2 T}|X|^{2}
$$

or,

$$
S_{x x}(f)=\lim _{T \rightarrow \infty} E\left\{\frac{1}{2 T}\left|\int_{-T}^{T} \mathrm{x}(t) e^{-j 2 \pi f t} d t\right|^{2}\right\}
$$

After the calculation of PSD, it is rewritten in manner of logarithmic as below Eqs. (5) and (6):

$$
P_{x x}(f)=10 \log _{10}\left(S_{x x}(f)\right)
$$

or, it becomes

$$
P_{x x}(f) \propto 20 \log _{10}(X)
$$

Here Pxx is in $d B$ (Decibel) unit.

\section{FERRORESONANCE PHENOMENA AND SYSTEM MODELING}

Ferroresonance phenomena due to the characteristic feature makes sudden jumps in the voltage and current. In this case also it includes the nonlinear properties. Ferroresonance event in the long transmission line, the system displays chaotic behaviour. As an application, Oymapinar-Seydisehir model of $380 \mathrm{kV}$ Electric Power Network in Turkey is presented in Figure 1. MATLAB Simulink model is used. Modelling the actual values are used for all parameters. General parameters for the electrical equipment are given in Table 1. Simplified model of the power transmission line is shown in Figure 1. 


\section{IRTITE}

Ipplied Researreches in Technics, Technologies and Eductation Journal of the Faculty of Technics and Technologies, Trakia University https://sites.google.com/a/trakia-uni.bg/artte/

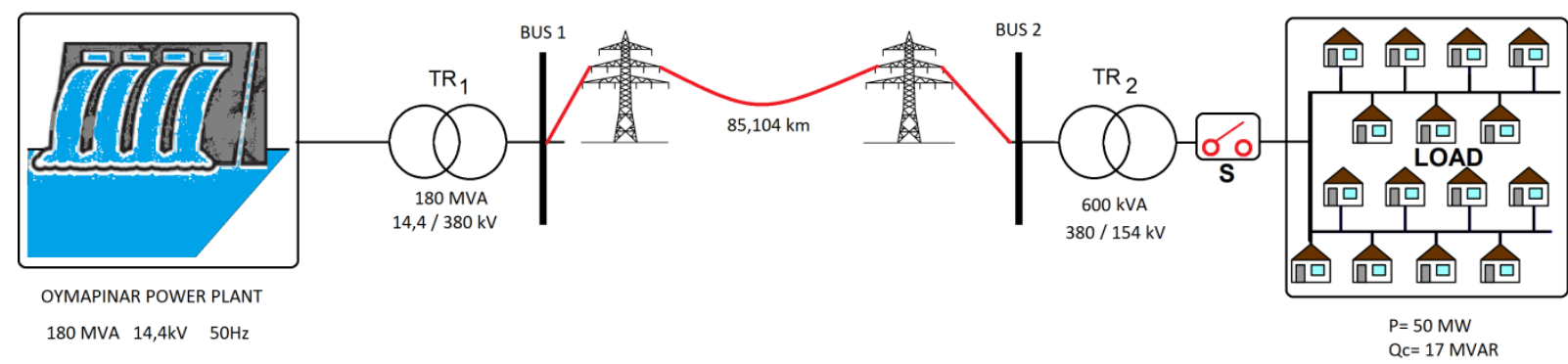

Figure 1. Simplified Model of Oymapinar-Seydisehir line for West Anatolian Power Network in Turkey

Table 1. Parameters of electrical components used for Oymapinar-Seydisehir line

\begin{tabular}{|l|l|}
\hline Electrical Components & Parameters \\
\hline Generator & $180 \mathrm{MVA}, 14.4 \mathrm{kV}, 50 \mathrm{~Hz}$ \\
\hline Transformers & TR1:180 MVA, $14.4 \mathrm{kV} / 380 \mathrm{kV}$ \\
& TR2: 600kVA, 380kV/154kV \\
\hline Lines & T Line(B1-B2): $85.104 \mathrm{~km}$ \\
& R: $0.2568 \Omega / \mathrm{km}$ \\
& L: $2 \mathrm{e}-3 \mathrm{H} / \mathrm{km}$ \\
$\mathrm{C}: 8.6 \mathrm{e}-9 \mathrm{~F} / \mathrm{km}$ \\
& Line(B2-B3): R: $1 \Omega, \quad$ L:1e-3 H \\
\hline Loads & L1:P=50 MW, QC=17 MVAR \\
\hline Switch & S: $2.5-5$ sec.- On \\
& $0-2.5$ sec.- Off \\
\hline
\end{tabular}

To indicate the ferroresonance effect, voltage variation for single phase (Phase $R$ ) in the model can be give Figure 2. Here, Figure 2 shows the voltage variations to be occurred in the case of removing the load through the switch $S$ (at $2.5 \mathrm{nd} \mathrm{sec}$.), which takes place at the end of the TR2.

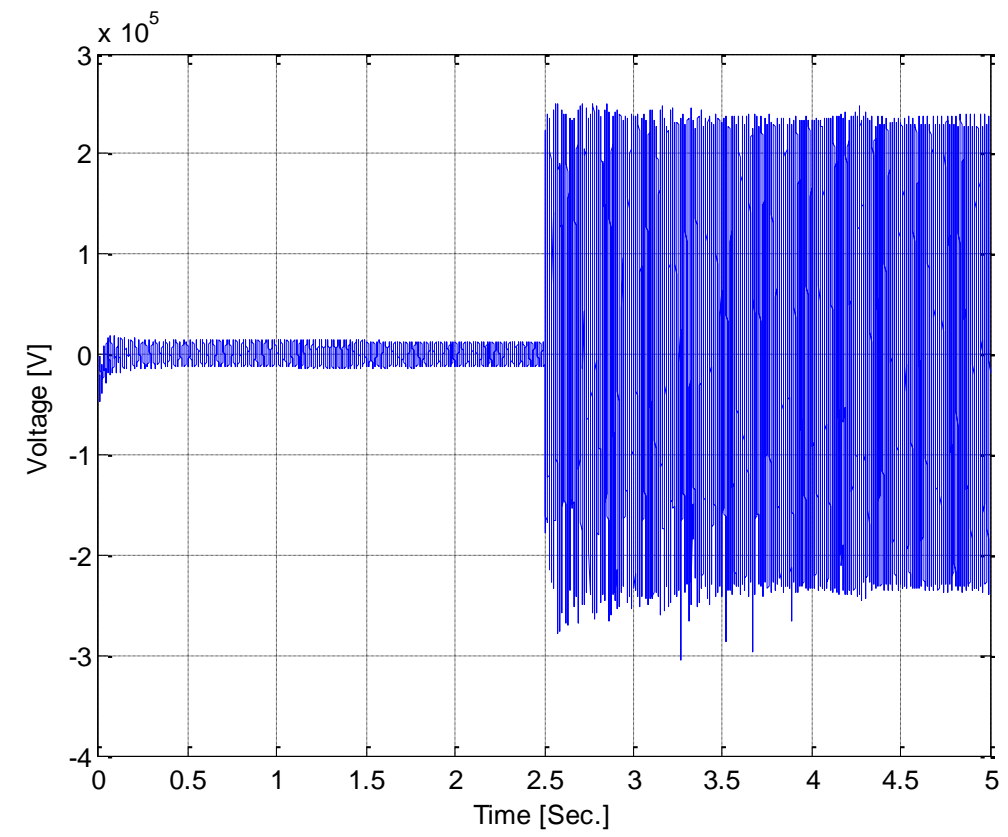

Figure 2. Overall data of the voltage variation for phase-R.

IRTIIE Vol. 4, No. 4, 2016 ISSN 1314-8788 (print), ISSN 1314-8796 (online), doi: 10.15547/artte.2016.04.006 


\section{ARTIIE

According to the Figure 2, over voltage variations are observed as a result of the ferroresonance effect by the switching.

\section{ANALYSIS}

As an application of the ferroresonance data, at first, its spectrogram is presented. In this presentation, which is shown in Figure 3, both of the time domain and spectral domain presentations is given by use of a joint amplitude axis. Also, its time-frequency presentation can be shown on a two dimensional plane. Hence all information about the data can be presented by this figure. However, it uses the normalized frequency value in $\mathrm{Hz}$ unit. Namely, the frequency axis is scaled by $(0-1) \mathrm{fs}$, where $f_{s}$ is sampling frequency at $4.4 \mathrm{kHz}$.

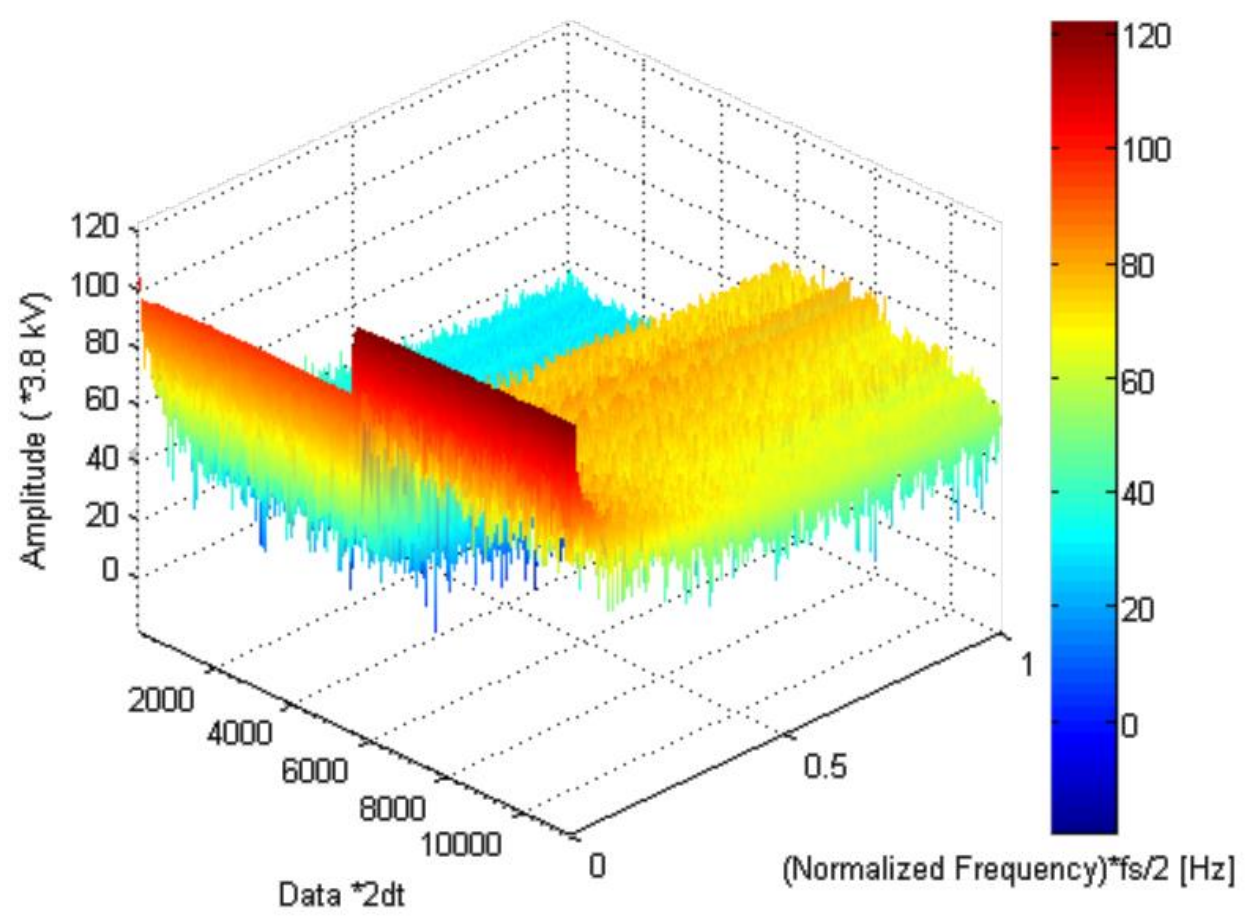

Figure 3. Spectrogram of the all data.

As seen in spectrogram, the data has a non-stationary characteristic. The ferroresonance event starts at 2.5 seconds with the time scaling of $2 \mathrm{dt}=2 / \mathrm{fs}=0.45 \mathrm{~ms}$ as seen in Figure 3 .

After the spectrogram calculation, all data can be participated as stationary data for each parts of before and after the ferroresonance event. And, therefore the power spectral density function (PSD) is calculated for each separated parts of all data. These calculations are presented as shown in Figures 4 and 5. 


\section{IRTTL $<>$}

Ipplied Resseirlores in Technics, Technologies and Educration Journal of the Faculty of Technics and Technologies, Trakia University https://sites.google.com/a/trakia-uni.bg/artte/

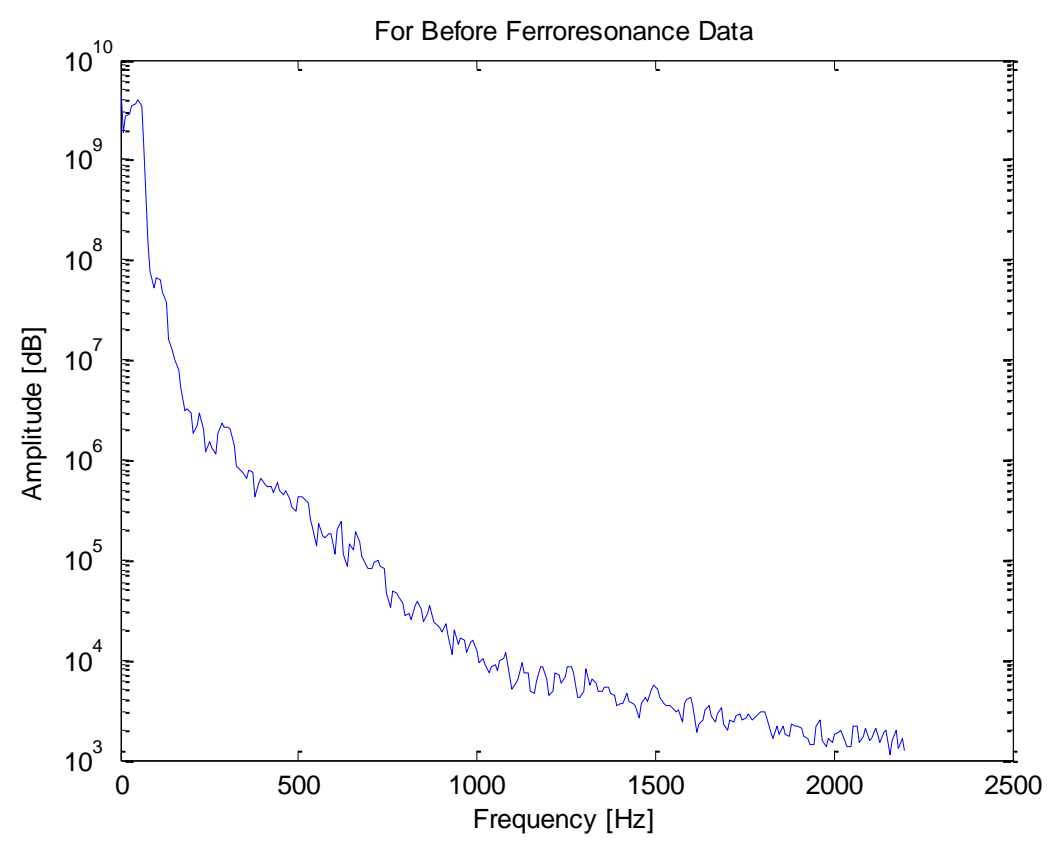

Figure 4. Logarithmic PSD for the data before the ferroresonance.

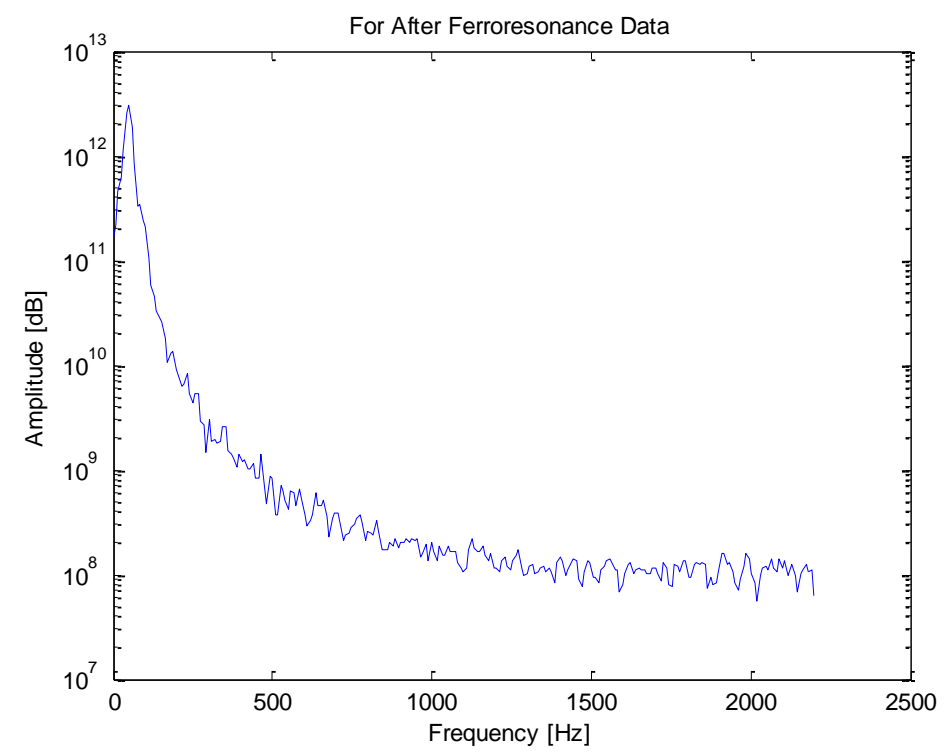

Figure 5. Logarithmic PSD for the data after the ferroresonance.

\section{CONCLUDING REMARKS}

As final results of this study, comparison of the PSD calculations are presented as seen in Figure 6. Where, considering the two spectral situations presented in Figure 6, the spectral gain (Amplitudes in $\mathrm{dB}$ ) increasing is observed by depending on the frequency values. In this manner, it can be said that: While the gain is at around $60 \mathrm{~dB}$ at $50 \mathrm{~Hz}$, it becomes $85 \mathrm{~dB}$ for $1500 \mathrm{~Hz}$. Hence, this property can be interpreted as an effect of the ferroresonance phenomena and it can be directly related with the over voltage as seen in Figure 1.

IRTTE Vol. 4, No. 4, 2016 ISSN 1314-8788 (print), ISSN 1314-8796 (online), doi: 10.15547/artte.2016.04.006 


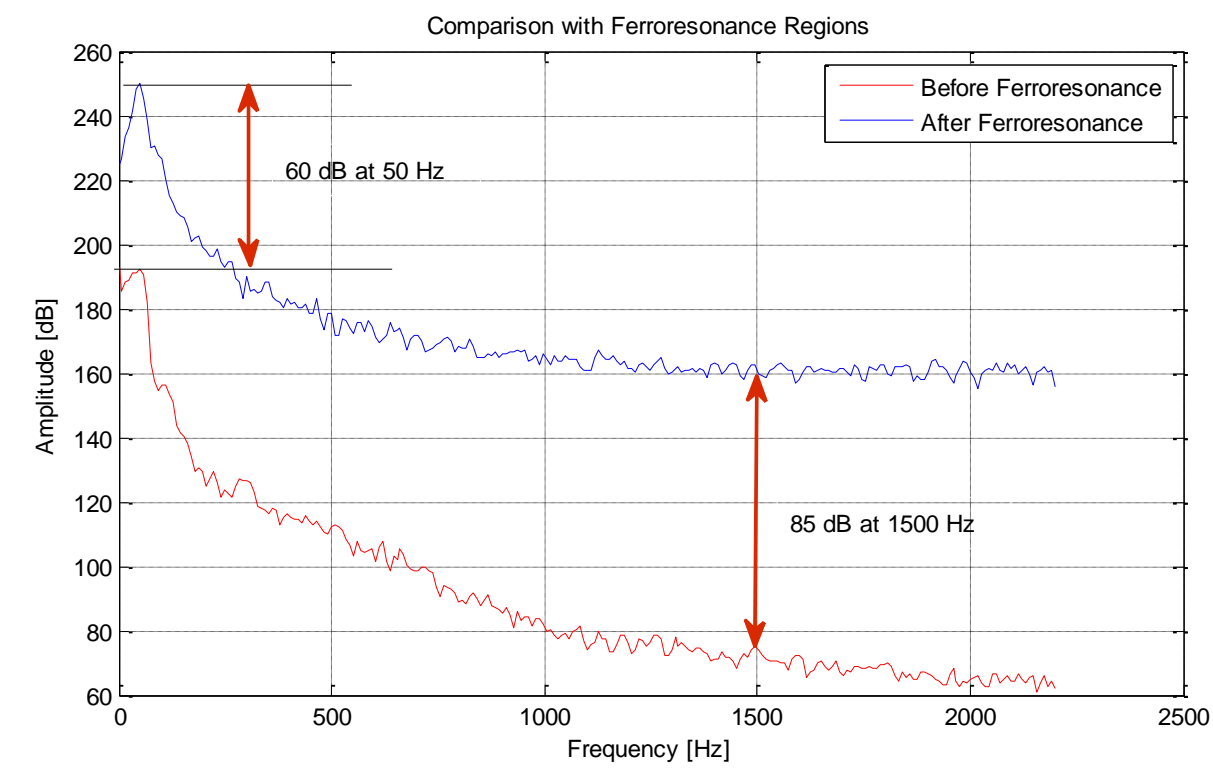

Figure 6. Comparison of the Logarithmic PSDs for the ferroresonance data.

\section{REFERENCES}

[1] Ferracci P. (2002). Ferroresonance, Cahier Technique No.190, Group Schneider Technique Publication, (2002).

[2] Jacobson D.A.N., Swatek D.R., Mazur R.W. (1996). Mitigating Potential Transformer Ferroresonance in a 230kV Converter Station, Transmission and Distribution Conference, Canada, 15-20 September (1996), pp. 269-275.

[3] Dugan R.C. (2003). Examples of Ferroresonance in Distribution Systems, IEEE Power Engineering Society General Meeting, Vol. 2, ISBN: 0-7803-7989-6, July (2003), pp.12131215.

[4] Yıldırım S, Akinci T.C., Şeker S, Ekren N. (2009). Determination of The Characteristics for Ferroresonance Phenomenon in Electric Power Systems, World Academy of Science, Engineering and Technology, Vol. 55, ISSN:2070-3724, Oslo, Norway, 29-31 July (2009), pp. 108-112.

[5] Akinci T.C, Ekren N. (2011). Detection of the Ferroresonance Phenomenon for an Electric Power Network Using the Spectral Methods, Acta Scientiarum. Technology, Vol. 33, No. 3, pp. 273-279.

[6] T.C Akinci S Şeker, N Ekren, S Yildirim (2013). Continuous Wavelet Transform for Ferroresonance Phenomena in Electric Power Systems" International Journal of Electrical Power \& Energy Systems, Vol. 44, No. 1, pp.403-409.

[7] B.A. Mork, D.L.Struehm (1994). Application of Nonlinear Dynamics and Chaos to Ferroresonance in Distribution Systems", IEEE Trans. On Power Delivery, Vol.9, No.2, pp.1009-1017.

[8] T.C. Akinci, S Şeker, N Ekren. Spectral Analysis for Signal Based on Ferroresonance Phenomena in Electric Power System, International Conference Engineering, Technologies and Systems TechSys'2009, Fundamental Sciences and Applications, Vol.14, May 29-30, Plovdiv, Bulgaria.

[9] MATLAB (2016), The Language of Technical Computing. [Online]. Available: http://www.mathworks.com/help/matlab/index.html [2016-07-11]. 